\title{
Systems and Others: Inclusion and Agency in Willis and Associates' CARLA Platform
}

\author{
MEREDITH SATTLER \\ California Polytechnic State University San Luis Obispo
}

Twenty years before the 'Digital Turn,' the architecture firm of Beverly Willis and Associates innovated the Computerized Approach to Residential Land Analysis (CARLA) workflow. CARLA captured a range of non-human others, within a systems-based environmental design process, developed to optimize the cost and environmental impact of largescale residential development in challenging hillslope sites. Emerging from the confluence of environmental ethics, novel policy, economic depression, and the dawn of Computer Assisted Overlay Mapping, CARLA not only redefined the firm's scope of services to attract large developer driven projects such as Oahu's Aliamanu Community for Military Housing project, which produced 2,600 units of housing, safely, within a volcanic caldera, but simultaneously prototyped complex systemic computational design strategies years ahead of their ubiquitous use within design firms. In the 1970's, CARLA leveraged the use of 'big data' and algorithms in the design process thereby rehearsing contemporary ethical debates surrounding agency in systems thinking and inclusion, through the strategic formation of a hybrid digital-analog, and ultimately political, design platform.

\section{FROM STATES TO SYSTEMS}

In 1978 enlisted Army, Navy, and Marine Corps personnel and their families began moving into the newly constructed Aliamanu Valley Community for Military Family Housing which sat within an inactive volcanic caldera near Pearl Harbor, Hawai'i. Aside from its unique site, on the surface this 542 acre, 2,600 residential unit development appeared similar to countless others constructed in the U.S. between the late 1950's and 1980's, despite the fact that it was the first built community predominantly designed using computational code. Yet it's precisely the caldera's unstable sloping site that initially drove the project's radical means of production, from design through construction. Beverly Willis and Associates' Computerized Approach to Residential Land Analysis, affectionately known as CARLA, facilitated the integration and analysis of diverse environmental conditions while evaluating their impacts on overall project costs and performance, with nearly real-time feedbacks. The project couldn't have been produced within its very reasonable \$115 million (1975 dollar) budget and tight time frame without CARLA, which generated rapid iterations, effectively prototyping systemic parametric design process the likes of which we still struggle to leverage systemically in architectural production today. Revisiting the development of CARLA's computationally driven production process affords a reexamination of our discipline's current relationships to production as informed by its conceptualization of relationships between systemic ecologies, inclusion, agency, tooling, politics, and ethics.

CARLA converged in response to an entanglement of American cultural crises. Each year of the early 1970's brought increasing economic, political, and environmental strife which had grave implications for the practice of architecture. Skyrocketing inflation and unemployment were unsuccessfully curtailed by "Nixon Shock" economic policies, game-changing U.S. EPA environmental regulation rapidly altered business protocols, and in 1971 housing starts "... reached a rate of 2,235,000 units, their highest level in the postwar period." ${ }^{1}$ Simultaneously, nonresidential construction was declining. In 1973 the Oil Embargo created a perfect economic storm that brought the construction industry, along with most others, to a screeching halt. "The result was a serious recession during the 1970's that decimated if not closed many architectural offices." ${ }^{2}$ From 1970 to 1972 Willis's firm averaged approximately 40 projects on their books per year, in 1973 the firm was down to 19 and in 1974 they bottomed out at $8 .{ }^{3}$

Starting in the late 1960's, Willis was keenly aware of her firm's, and the nation's, increasing economic vulnerability. While a defensive strategy, incorporating environmental risk mitigation, fueled her desire to diversify the portfolio of services offered by WAI, her entrepreneurial spirit welcomed forays into a series of extra-disciplinary endeavors which not only enriched office culture but also provided enough work to keep her employees on payroll. ${ }^{4}$ She had been working on several novel market-defining products that leveraged environmental, economic, and emergent computational technologies which created options and efficiencies previously unexperienced in the profession. As opportunities presented themselves, WAI nimbly choreographed hardware, software, and novel architectural design process into CARLA, which ultimately forecast and rehearsed three significant current modes of architectural production: data-driven design, parametric design, and systems design processes. Anticipating what Pierre Bélanger has identified as the "...moment when environmentalism began to fail and ecology emerged between the "70's and '90's." ${ }^{5}$ CARLA ultimately wavered between these environmentalism and ecological paradigms, utilizing early computational technologies to incorporate the agency of non-human others via 


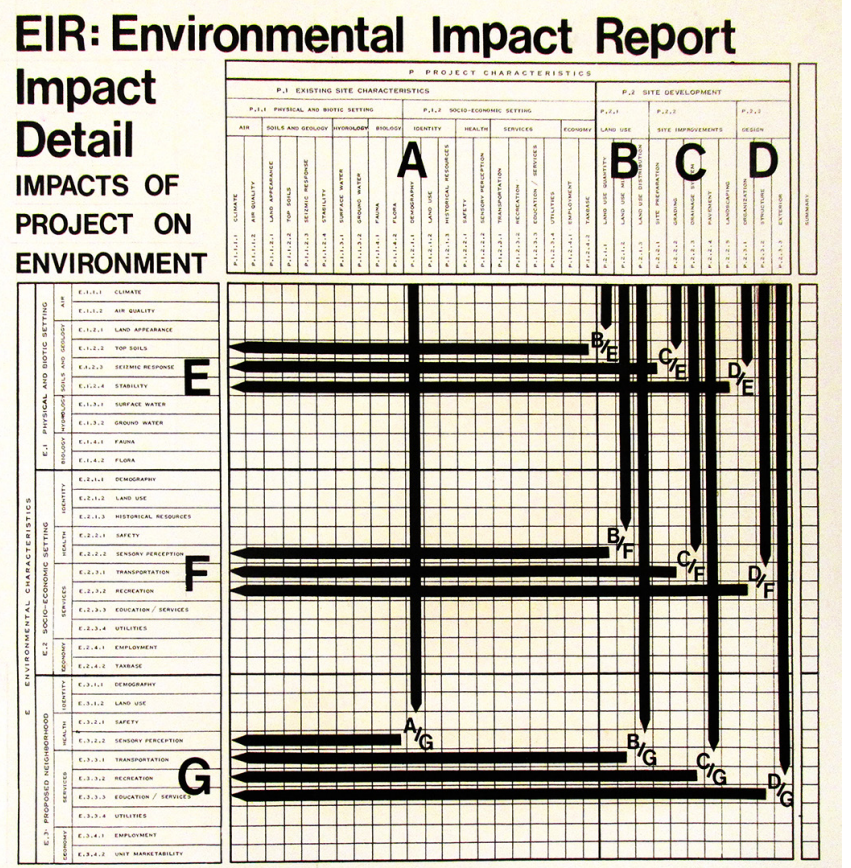

Figure 1: Environmental Impact Report Impact Detail Matrix: WAI's EIR Analysis of Environmental and Project Characteristics - Ms1992-019, Special Collections, University Libraries, Virginia Polytechnic Institute and State University

the development of probabilistic code to optimize grading, siting, civil, space planning, and costing of large scale residential developments within hillslope topographies. These topographies had proven problematic for large-scale suburban residential developers for over 25 years, particularly in California. At the time CARLA was significantly more efficient than the analogue planning and architectural workflows of the day, minimizing project risk, maximizing project budgets, providing more client control in the decision making process, and providing WAI a significant competitive edge during a severe economic downturn.

\section{RETOOLING CONSTRUCTED ENVIRONMENTAL FEEDBACKS}

In 1970, in astoundingly rapid succession the Federal Government passed the National Environmental Policy Act (NEPA), the EPA was founded, and the State of California's Environmental Quality Act (CEQA) was legislated. These regulations were astonishing in their ambition and scope, and upon coming into force they proved challenging regulatory cocktails, particularly problematic to implement and enforce. Willis's San Francisco based firm was situated near the front line of CEQA. "Six of our major multifamily projects were put on hold by the California legislation. To avoid bankruptcy and to get permits for our projects, I met with state officials and learned they had not developed guidelines by which to evaluate projects like mine." ${ }^{\prime 6}$ It was clear that the Act's implications for the planning and development industry were deeply significant and simultaneously incompatible within current workflows.
Willis was no stranger to politics and the larger San Francisco business community. She had to be as "...the only woman in San Francisco with her own firm...She spent time with developers, businessmen and political figures, as well as with architects, and she inevitably entered the architecture of politics and planning."7 Willis initiated a pro-bono relationship with state officials to contribute to the development of urgently needed protocols which ultimately became the Environmental Impact Assessment (EIA) administrative procedures. ${ }^{8}$ She soon became head of the Facility Council. ${ }^{9}$

At the time, Willis lacked the comprehensive environmental knowledge necessary to ensure that overarching CEQA goals remained intact through new design and approvals processes. But she proved an intuitive systems thinker, studying and synthesizing geology, biology, ecology, and economics to better understand the larger picture of CEQA's intent. ${ }^{10}$ Later she would write:

\footnotetext{
"The various participants [in the Environmental Design profession] tend to look myopically at the system parts (elements) and see only the 'parts' within their own sphere of activity. However, each has an impact on the other. Because of this myopic viewpoint, sometimes various elements work against each other...[this] often hampers and restricts environmental protection rather than enhancing and protecting it." ${ }^{11}$
}

Willis's after hours work on the EIA ultimately had a profound effect on the firm's production and scope of services, which were welcomed by many of Willis's native California employees who shared her environmental ethos. WAI developed internal office procedures for authoring Environmental Impact Reports (EIR's), and included EIR's within the scope of their work, both at the initiation of their projects, and as a stand-alone service. Not only was the EIA service a novel product in the market space, generating additional revenue and notoriety for the firm, it also facilitated the immediate State permitting approvals of WAI projects.

But its effect was far more structural in its shift of the firm's conceptual underpinnings about design's relationship with the environment. Projects were conceived and ultimately initiated through increasingly environmental frameworks which went well above and beyond CEQA regulation requirements. They included analysis of feedbacks between 63 environmental issues, sensitivities, and impacts ranging from existing site and biotic characteristics to socio-economic settings. Flow-chart diagrams guided project designers through the process of generating a comprehensive evaluation matrix within which each element could be analyzed in relation to the whole. 


\section{ENVIRONMENTAL DATA FLOW CHART}

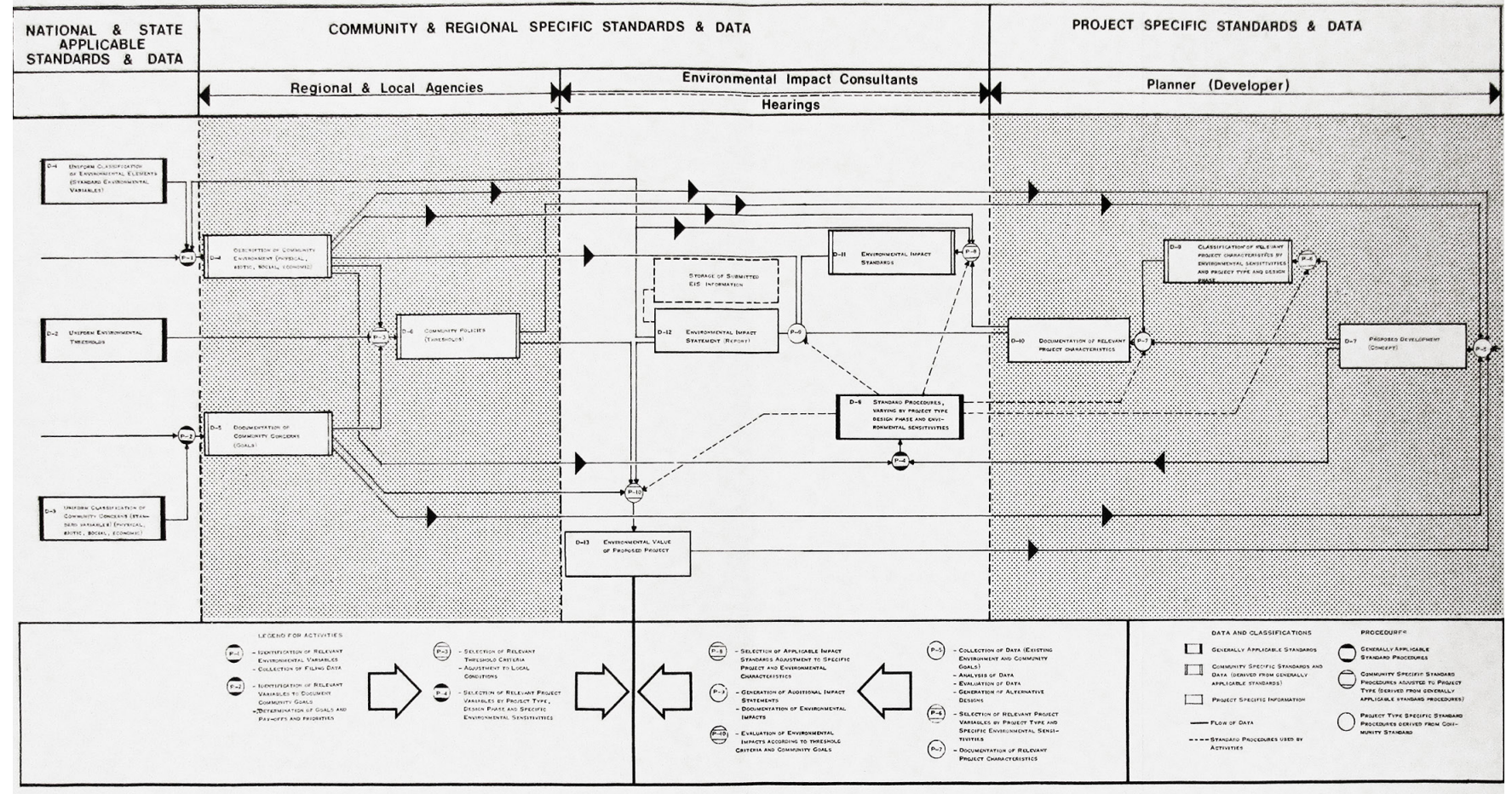

Figure 2: WAI's Environmental Data Flow Chart - Beverly Willis Architec tural Collection, Ms1992-019, Special Collections, University Libraries, Virginia Polytechnic Institute and State University

\begin{abstract}
"This form of documentation makes it evident, that each planning variable (e.g. grading) has an impact on many environmental variables (e.g. land forms, wildlife... etc.) And conversely each environmental variable (e.g. erosion potential) is affected by many planning variables (e.g. grading, tree removal... etc.)"12
\end{abstract}

With this new environmental capacity, Willis leveraged the current economic strength of housing starts ${ }^{13}$ by providing environmentally based consulting and design services targeted at large suburban residential developers building on challenging hillslope sites. Despite the tension between "Every Family's Right"14 to own a piece of the American Dream and the "residential ills in the heartbreak hills of southern California,"15 (otherwise known as landslides), which consistently claimed lives and property, development continued at a rampant pace.

\footnotetext{
"Though there are no nationwide statistics on hillside development, there is no doubt that construction tore into the hills in many parts of the nation after 1945. One of the most popular houses of the 1950s - the split-level-was designed in part to suit lots on steeply sloped ground. ${ }^{16}$
}

The combination of increasing public concern over life safety risk with new environmental regulation proved a challenge for planners and policy makers. In the hilly Bay Area, effective regulation wasn't put in place until the late 1970's. ${ }^{17}$ In the meantime, it remained up to private developers to determine how much risk they were willing to take on. Increasingly the interface between environment and building, as understood through the datum of the groundplane, became a driver of design process at WAI.

This work instigated the firm's official expansion into the field of environmental planning. Willis understood that a product providing developers with better information and hence, more powerful decision making potential, would be intensely profitable. "But WAI "...needed a way to evaluate and document vast acreage to determine the locations of environmentally sensitive land, unstable soils, and natural drainage, and to see environmentally what would happen when we build on any such land."18 This required new multiscalar tools for spatial mapping and analysis, that paralleled new regulatory protocols, in order to fully integrate environmental design into the firm's architectural production.

Willis diagrammed CEQA's implications for architectural workflows, from both perspectives of designers and regulators. These diagrams, which eventually took the form of systemic algorithms, became a shared language and ultimately a habit of mind within the office. Once mated with computational programming, they would facilitate the development of CARLA. 


\section{REHEARSING TRANSFORMATIONS FROM GIS TO ENVIRONMENTAL DESIGN}

Willis knew that "SOM used computing for Human Resource management and financial evaluation"19 but she was unaware of any firms utilizing computation for design. Willis "...envisioned a computer program that would allow me and my firm to solve the most difficult challenges facing the land planner, particularly construction on hillside sites that involved substantial cut-and-fill land areas." ${ }^{\prime 20}$ At the time, computational spatial mapping and analysis was relatively novel. In the early 1970 's only large corporations, governments, and universities were in the field. While several institutions in North America, Great Brittan, and Australia had begun to push the 2-dimensional mapping and analysis envelope into 3-dimensional spatial computation, "...a decade after the first maps were computerized, there were only about 40 people in the world using the technology." "The computer had not yet entered the mainstream." 22

Conceptually, Ian McHarg's "Map Overlay Methodology" provided a design method that operated both as an analytical and a generative design tool. It produced "...layers that are causal and chronological"23 to determine land use suitability based on hierarchies of features. Willis looked for the expertise required to build a dynamic computational platform in McHarg's vision ${ }^{24}$ and found it at the Harvard Laboratory for Computer Graphics and Spatial Analysis (in the basement of the GSD) and the USGS Kansas Geological Survey. In particular, WAl leveraged two individuals from Harvard that were critical in conceptualizing, coding, and implementing CARLA: Eric Teicholz and Jochen Eigen, the latter joined WAI full time in 1972.

By 1973 WAI had a partial version of CARLA up and running, but not without challenges. WAI was comprised of about 35 designers and 3 programmers. As the computational aspects of CARLA exerted more influence on the design process, tensions arose between computational and more traditional design processes. Once again, Willis leveraged systems analysis to deconstruct "...the often intuitive process of land planning... This meant working with each member of the firm to determine how they saw the planning steps involved and to document an overall system approach to which all could agree." ${ }^{25}$ These discussions revealed a necessary keystone in CARLA's structure: The Planning Unit.

"The 'Planning Unit' is a planning module computationally defined. It is one of the basic tools used in CARLA, encompassing not only envelope and interior elements, but also elements within the immediate environment." ${ }^{26}$ Planning Units could be any building program or site type (lot subdivision, for example) and any structural system. They were comprised of quantifiable data such as: number of stories, square footage, number of room types, and parking per unit. Eventually the firm built a database of over 3,000
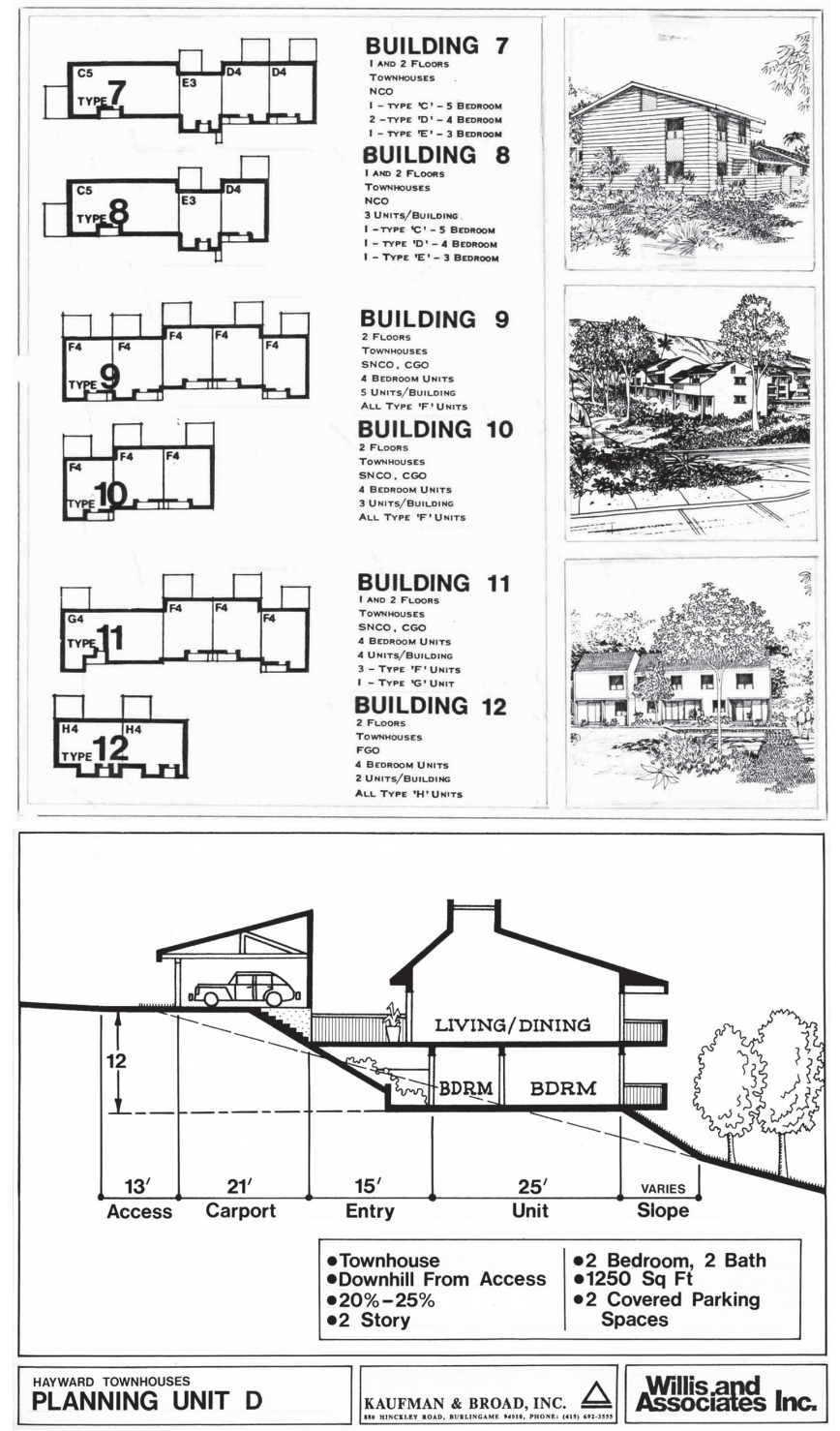

Figure 3: Promotional materials utilizing Planning Unit data to illustrate housing units - Beverly Willis Personal Archive, Branford, CT

pre-programmed Planning Units and had the capability to program any existing successful unit that client provided. ${ }^{27}$ Ultimately, the Planning Unit drove crucial decisions regarding density, construction costing, and marketing amenities (including design) to the forefront of the design process, greatly reducing the time required to do residential land planning.

In order to incorporate more environmental information into the design process, WAI worked with the Kansas Geological Survey on and off from 1974 to 1979 to further incorporate their SURFACE II topography analysis software into CARLA's platform. "With Surface II's plotting program and planning units in hand, WAI Director of Research and Development, Eigen, wrote the code to allow a series of manual and computer programs to interface." ${ }^{28}$ It soon became clear that 


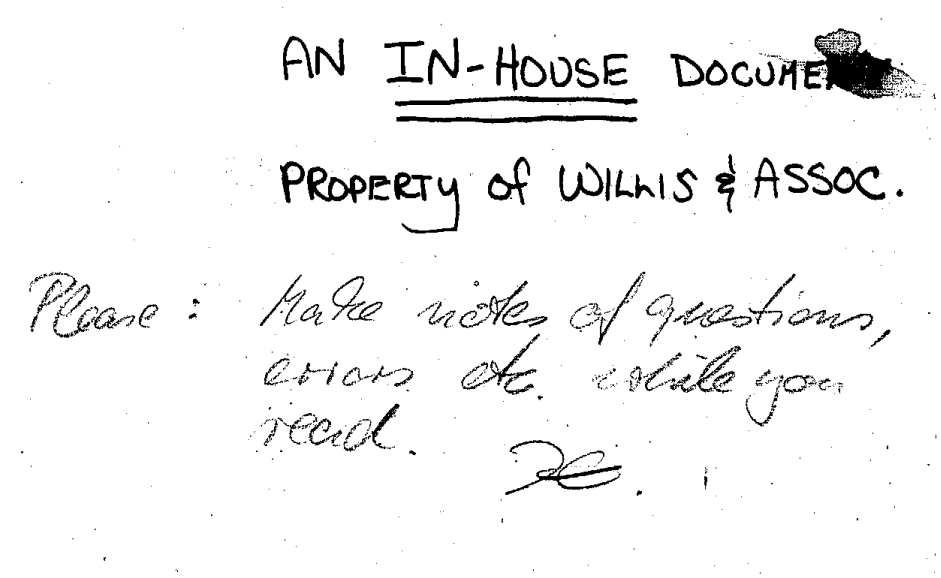

COMPUTER MANUAL FOR THE NON-SPECIALIST

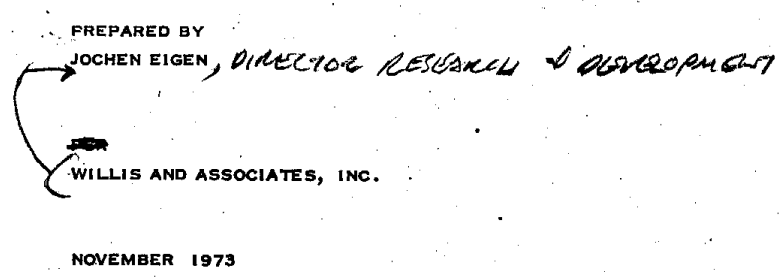

Figure 4: Select pages from Eigen's Computer Manual for the Non-Specialist, WAl internal document - Beverly Willis Architectural Collection, Ms1992-019, Special Collections, University Libraries, Virginia Polytechnic Institute and State University

development of CARLA's "Three Step Approach" which integrates site and building issues at each step. The process began with initial project information: accurate topos, soils maps, marketing, and user need criteria. First, physical and environmental characteristics of the existing site were mapped. Then, applicable Planning Units for the project were selected utilizing the Planning Unit Analysis program (PUA). Next, a series of optimization algorithms were run including the Site Area Allocation (SAA), the Massing of Alternate Configurations (MAC), and the Massing of Alternate Configurations Cost (MAC\$). At this point, if the costs exceeded the budget the process was rerun to produce new development concepts until the budget was met, and the developer and designer were satisfied with the overall plan. This process addressed a comprehensive suite of design issues including: slope analysis, minimization of grading qualities, avoidance of costly grading (blasting), minimization of hillside foundations, naturalization of storm drainage, maximization of surface storm drainage, optimization of gravity powered water flow, geology/soils analysis, minimization of foundation cut, minimization of utility trenching cost, minimized length of sanitary sewer, optimization of roadway locations, minimization of road bed cost, environmental
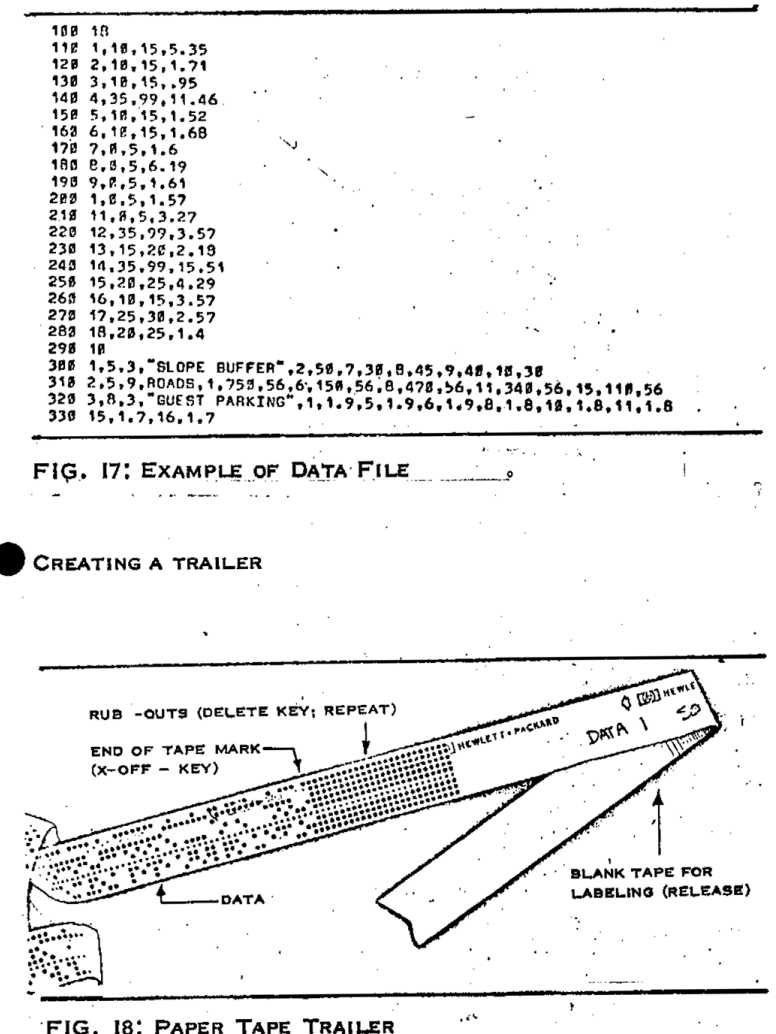

analysis, minimization of cooling cost by siting buildings to reduce solar load, optimization of natural ventilation, onsite utility analysis, analysis of offsite utility potential, best use of offsite utilities, optimization of offsite sewer alignment, water source evaluation, and combined overhead and underground electrical. Many of these were the result of hybrid computational-analog processes.

"The computer graphic information reports were represented either in the form of topographical site perspectives, contour maps or as a sequence of numeric values organized within a template matrix that allowed the architect to identify the optimal relationships and planning concept. This work then became the basis for presentation materials that were used to introduce the client/developer to the proposed designs. In many cases a site topographical map was used as the base to which a variety of the contour studies were over-layed upon via transparent materials." 29

In order to align digital and analog workflows, it was critical that everyone in the office have an appropriate understanding of the novel technologies with which they were co-designing. In 1973, Eigen authored an internal WAI document: "Computer Manual for the Non-Specialist" targeting "...the professional who has recognized the usefulness and importance of the computer for an effective and responsive fulfillment of his professional task, but for whom the computer is no more important than any other tool modern 
spatial analysis could accomplish ever larger varieties of tasks that were somewhat mundane for the architect, such as assisting in the solution of Fire Safety Layout.

Willis incorporated staff input about planning processes into the that:

"It is enough to visualize the computer as a person with the following basic attributes:

- Having an extremely large and accurate memory;

- Being extremely fast and reliable;

\section{But}

- Being extremely dumb (but predictable);

- Having a somewhat limited capacity of communication"31

He went on to explain that "...the cost effectiveness of using a computer is basically dependent on the payoff between the effort involved in explaining to the computer what to do and the savings in manual work." ${ }^{\prime 32}$ It is a 48 page document that recasts the computer as a strategic tool for design at WAI, explains the hardware and how it interfaces, and walks the user through the basic steps to log into the three timeshare computing mainframes (Computer Science Corporation, Tymeshare, and General Electric) that WAI contracted with. ${ }^{33}$

\section{CARLA'S PROOF OF CONCEPT}

In May of 1973, Mr. Eugene Rosenfield of Kaufman \& Broad, Inc. (K\&B) awarded Willis and Associates their first CARLA commission. K\&B had purchased hillsloped land in Hayward, CA from another developer who sold, after spending 18 months in a traditional planning process which was unable to produce a design within budget. K\&B was looking to build a suburban development called "Crestview Homes," consisting of 120 townhomes on 20 acres with a $35 \%$ lower budget than their failed competitor. CARLA was particularly adept at costing because it utilized actual quantities for cost evaluations, which proved significantly more accurate than standard construction cost estimating procedures of the time (based on historical rule-of-thumb). WAl used their philosophy of minimizing land use in order to maintain more open space while simultaneously keeping construction, and associated costs, down by designing for less grading, less civil engineering, fewer roads, and simpler building foundations. WAI successfully tested CARLA on the Hayward project, producing a viable plan within budget, in a record 15 working days. ${ }^{34}$

\section{PROCESSING CALDERA}

In 1975, CARLA landed Willis the largest project of her career, and ultimately the largest housing development the U.S. military built to date: Aliamanu Valley Community for Military Family Housing. With a \$115 million budget (likely a billion dollar project today), a nine month design time, and two year build-out, WAI was uniquely positioned to accomplish it. The site was 524 acres, one and a half miles long, with 525 townhouse duplexes and cluster buildings ranging from 1-3 stories. There were multiple town centers with schools and retail. Containing a total of 2,600 units, which would ultimately house 11,500 occupants, ${ }^{35}$ and constructed primarily of wood frame with stucco and shingle or wood siding finishes. One of the client goals was to provide military families with a more typical American residential atmosphere.

Aliamanu was literally and metaphorically a volcanic situation. Sited within an inactive volcanic crater previously used as a massive bomb and shell dump during WWII, the crater walls of the site both cradled and separated the community from adjoining areas. Ammunition storage caves had been carved into the steep volcano slopes surrounding the valley and only one crater wall was gentile enough in slope to be buildable. "The site plan and the building plans evolved from the nature of the site, the demographics of the military community and the very modest budget." ${ }^{36}$ The project was constrained by labor, long travel distances for construction materials, a high public profile, and an exceedingly tight time frame. Like Crestview, WAI was the second firm to work on the project after an initial failure. Also similar to Crestview, CARLA'S design required $40 \%$ less cut and fill than the previous firm.

The client, the Department of Army U.S. Corps of Engineers Pacific Ocean Division, brought their military disposition to the management of the project. WAl's systems approach and efficiency not only successfully produced the project, but lubricated the challenging client relationship.

"Willis recognized early indicators that traditional architectural and land planning practices could not keep pace with the evolving demands and complexities facing the residential development industry. Her perception and willingness to risk investing in the research and development of computer software positioned her firm well ahead of the curve, uniquely preparing them to address the difficult 1970's building climate. Indeed, while many firms suffered during 1970's two major building depressions...[WAl] experienced an increase in activity with 1975 billings generating an estimated 2.2 million." ${ }^{37}$

Despite the project's success, and the fact that it saved WAI from the worst of the economic downturn, its computationally driven pace and logistics pushed all parties involved to their physical limit. The toll was perhaps most severely experienced by Willis herself. As a woman, there was more than just her firm at stake in the success of the project.

After Aliamanu, Willis's desire to work on a smaller architectural scale, focusing on spatial and material experience, increased. While the firm continued to attract projects that 
leveraged CARLA's unique strengths, such as the IRS's new computer centers, ${ }^{38}$ Willis began aggressively pursuing a different type of project. ${ }^{39}$ Though in retrospect, the market potential for CARLA is clear, at the time Willis was unsure about its widespread viability.

"I never packaged CARLA for sale as a program, as planning and architecture firms were not using computers (consequently, [there was] no market). The developers who built multifamily housing (condos and rental apartments) were CARLA's primary market. However, in the late 70s, this market dwindled out. Land suitable for single-family homes could easily be sub-divided without need of a computer program like CARLA. This also was the era that predated the desktop computer, so any investment in plotting systems (later known as CAD) was then substantial. A market could have been in large engineering firms, but I was too unsophisticated to know that then."40

\section{So CARLA quietly disappeared.}

\section{SYSTEMS, BIG DATA, AND NON-HUMAN OTHERS}

In WAI's marketing materials of 1974, CARLA figured prominently as a "...current "space age" technolog[y] designed to address the complexities facing builders, developers and environmental planners working in the 1970's." ${ }^{\prime 11}$ Therefore, a contemporary reexamination of CARLA begs consideration of 'space age' ethics of inclusion and agency of 'others' in design approaches, particularly in relation to dynamic environments, complexity, and multiple perspectives and epistomologies. Two key components of CARLA drive this reexamination: the increased agency of designers who make their own tools, and the application of design ideation and process, pared with more precise predictive capabilities, to disciplines outside of those traditionally engaged in design.

Because CARLA was produced and continuously modified from within WIA's office, it never operated as a 'black boxed' tool. Instead, it was continually subject to inquiry about how it performed and could be additionally leveraged. Through both intentional invention, and accidental discovery, the scope of CARLA's services expanded throughout the time it was utilized. Because CARLA emerged before design software was codified and stabilized, when parametric design was novel, computation and the designers' intuitive hand were seen as clearly hierarchied partners in the co-production of design. "In the CARLA process the computer is used to aid the planner and designer. It does not make decision for them. It does substantially aid the designer and our client to develop more creative ideas in a shorter period of time." 42

This clear insight into the strengths and weaknesses of the tool, additionally facilitated by the fact that the code was relatively simple and accessible, the programmers worked in the office, and the designers were happy to be relieved of certain mundane tasks, CARLA increasingly transformed design workflows and office culture. This largely transparent workflow, combined with manual input and analysis, mitigated potential for unintended environmental and political repercussions which can result from poorly informed design. CARLA's authors were clear about what they could conceptualize and design for, and what they couldn't. They constructed a process with relatively tight tolerances for the elements they could control such as $x, y, z$, coordinates, drainage patterns, and cost, and simultaneously left significant space for the elements they couldn't control, those more mysteriously behaving non-human actors, such as open space, flora, and fauna.

Ultimately, WAI optimized components of the design process they were reasonably confident would produce better build environmental performance, more closely aligned with desirable circumstances. CARLA reveals a rich mode of production, born from transparency, designers' engagement in the creation of tools for their own use in design process, responsiveness to circumstance, and incorporation of extradisciplinary knowledge. In the process, CARLA itself became a mechanism to incorporate extra-disciplinary people and processes into architectural design process while simultaneously providing a means to inspire the further incorporation of economic, regulatory, and environmental 'others.' This furthered the possibility of inclusion and access for novel information and potential actors, who in turn, furthered contributed to the trans-disciplining of WAl's approach. While CARLA's technologies and artifacts are dated, its process, and the thinking behind it, are shockingly relevant today.

\section{ACKNOWLEDGEMENTS}

The production of this article has been supported by the International Archive of Women in Architecture Center, Virginia Tech School of Architecture + Design, Milka Bliznakov Research Prize. The author wishes to thank Donna Dunay, Helene Renard, Dan Suchy, Nikki Potter, Geoff Zylstra, and the Society of Historians of Technology. Special thanks to Beverly Willis and Wanda Bubriski. Finally, thanks to the conveners of the 106th ACSA Annual Meeting.

\section{ENDNOTES}

1 Craig Swan and John Kareken, "Labor and Material Requirements for Housing," Brookings Papers on Economic Activity 1971.2 (1971): 347-348. While unintuitive given the depressed economy, the housing boom of the early 1970's was due largely to high demand (fueled by 5 years of low levels of housing starts and decreasing vacancy rates) combined with low interest rates and an abundance of available mortgages.

2 Leland M. Roth, A Concise History of American Architecture (New York: Harper \& Row, 1979): 475

3 Willis and Associates, Inc. Project Control Numbers Master List, pages 16-21. Beverly Willis Architectural Collection, Ms1992-019, Special Collections, University Libraries, Virginia Polytechnic Institute and State University.

4 Beverly Willis, personal interview with author, Branford, CT, August 1, 2015.

5 Pierre Bélanger, Going Live: From States to Systems (New York: Princeton Architectural Press, 2015): 3 . By “environmentalism" Bélanger is referring to its singular command-and-control spatial/temporal frameworks versus the indeterminate, indivisible, and unpredictable relational performance of "ecology." 
6 Beverly Willis, email correspondence with author, May 12, 2015.

7 Nicolai Ouroussoff, "An Image of Beverly Willis," in Invisible Images: The Silent Language of Architecture and the Selected Works of Beverly Willis, Beverly Willis. (Washington D.C.: National Building Museum, 1997): 99-104.

8 Within the architectural profession, this regulation is more commonly known as its final reporting mechanism, the Environmental Impact Report (EIR).

9 Sharon Lee Ryder, "Environmental Impact, Getting at the Issues," Progressive Architecture (June, 1974): 82-87.

10 Beverly Willis, personal interview with author, Branford, CT, November 6, 2014.

11 Beverly Willis, "The Environmental System Decision-Making Process," in Environmental Impact Analysis: Emerging Issues in Planning, ed. Ravinder K. Jain and Bruce L. Hutchings. (Urbana: University of Illinois Press, 1978): 187.

12 From Willis and Associates, Inc. EIR Office Methodology, page 7. Beverly Willis Architectural Collection, Ms1992-019, Special Collections, University Libraries, Virginia Polytechnic Institute and State University.

13 United States Department of Housing and Urban Development, Construction Reports: Characteristics of New One-Family Homes 1971 (Washington D.C.: United States Department of Commerce, 1971): 6.

14 Richard Pratt, "Every Family's Right," The Ladies' Home Journal 61.9 (1944): 36-7.

15 Richard H. Jahns, "Residential Ills in the Heartbreak Hills of Southern California," Engineering and Science 22 (December, 1958): 14-20.

16 Adam Rome, The Bulldozer in the Countryside: Suburban Sprawl and the Rise of American Environmentalism (Cambridge: Cambridge University Press, 2001): 121.

17 Thor H. Nilsen, Robert H. Wright, Thomas C. Vlasic, William E. Spangle, Geological Survey Professional Paper 944: Relative Slope Stability and Land-Use Planning in the San Francisco Bay Region, California (Washington D.C.: United States Government Printing Office, 1979).

18 Willis and Associates, Inc. CARLA: Computerized Approach to Residential Land Analysis Promotional Film Accessed on July 23, 2016: http://beverlywillis.com index.lasso?token. page=video\&session=user:475E301B11d9c204F1Ukx2922F 15\#video_6

19 Beverly Willis, email correspondence with author, May 12, 2015.

20 Ibid.

21 Lynn Greiner, "Putting Canada on the Map," The Globe and Mail 17 (2007). Accessed on July 6, 2016: http://www.theglobeandmail.com/technology/ putting-canada-on-the-map/article1092101/

22 Holly Hinnman, "3 Willis Design Innovation Descriptions," Beverly Willis Personal Archive Internal Document, 2005)

23 Ian McHarg, GIS World Interview, 1995. "Ian McHarg Reflects on the Part, Present and Future of GIS, 1995 GIS World Lifetime Achievement Award Winner," GIS World (October): 46-48.

24 For a complete history of the development of GIS see: ed. Timothy W. Foresman, The History of Geographic Information Systems: Perspectives from the Pioneers (Upper Saddle River: Prentice Hall, 1998), Nick Chrisman, Charting the Unknown: How Computer Mapping at Harvard Became GIS (Redlands: ESR Press, 2006), and ed. Gerald McGrath and Louis Sebert, Mapping a Northern Land: The Survey of Canada, 1947-1994 (Montreal \& Kingston: McGill-Queen's University Press, 1999).

25 Beverly Willis, email correspondence with author, May 12, 2015.

26 Jochen Eigen, Willis and Associates Computer Manual for the Non-Specialist (Internal Publication, 1973).

27 Willis and Associates, Inc. CARLA: Computerized Approach to Residential Land Analysis Promotional Film Accessed on July 23, 2016: http://beverlywillis.com/ index.lasso? token. page=video\&session=user:475E301B11d9c204F1Ukx2922F 15\#video_6

28 Beverly Willis, email correspondence with author, May 12, 2015.

29 Holly Hinnman, "3 Willis Design Innovation Descriptions," Beverly Willis Personal Archive Internal Document, 2005).

30 Jochen Eigen, Willis and Associates Computer Manual for the Non-Specialist (Internal Publication, 1973).

31 Ibid.

32 Ibid.

33 Because of the recession, which hit West coast air and space industries particularly hard, there was lots of underutilized computing capacity available for WAI at a reasonable price.

34 Willis and Associates, Inc. CARLA: Computerized Approach to Residential Land Analysis Promotional Film Accessed on July 23, 2016: http://beverlywillis.com/ index.lasso? token. page=video\&session=user:475E301B11d9c204F1Ukx2922F 15\#video_6
35 Willis and Associates, Inc. Aliamanu Project Summary. Beverly Willis Architectural Collection, Ms1992-019, Special Collections, University Libraries, Virginia Polytechnic Institute and State University.

36 Willis and Associates, Inc. Aliamanu Project Summary. Beverly Willis Personal Archive.

37 Sidney P. Allen, "Land Planning, CARLA races to get Job Done," The Chronicle (September 7, 1975)

38 "Selected because we were one of the only firms in the U.S. that understood computer functionality" Willis and Associates, Inc. IRS Computer Center Building Project Summary. Beverly Willis Architectural Collection, Ms1992019, Special Collections, University Libraries, Virginia Polytechnic Institute and State University.

39 Beverly Willis, personal interview with author, Branford, CT, August 3, 2015.

40 Beverly Willis, email correspondence with author, May 12, 2015.

411974 Willis and Associates marketing brochure. Beverly Willis Architectural Collection, Ms1992-019, Special Collections, University Libraries, Virginia Polytechnic Institute and State University.

42 Willis and Associates, Inc. CARLA: Computerized Approach to Residential Land Analysis Promotional Film Accessed on July 23, 2016: http://beverlywillis.com/ index.lasso? token. page=video\&session=user:475E301B11d9c204F1Ukx2922F 15\#video_6 